\title{
Effects of Receptive and Productive Tasks on Iranian EFL Students' Learning of Verb-noun Collocations
}

\author{
Mehdi Falahi \\ University of Isfahan, Isfahan, Iran \\ Email: Mehdi.Falahi442@gmail.com \\ Ahmad Moinzadeh \\ University of Isfahan, Isfahan, Iran
}

\begin{abstract}
The current study is an attempt to investigate the effects of receptive (reading three glossed sentences) and productive (completing a cloze task) tasks on learning English verb-noun collocations in an Iranian English as a foreign language (EFL) learning context. To this end, ninety four EFL university learners were divided into two experimental (reading and cloze) groups and one control group. To determine the effects of the tasks, the participants in all three groups were given receptive and productive collocation pretests aiming at examining their existing knowledge of collocation and posttests to measure the learners' gained knowledge of collocation after being exposed to the treatments. The results of a Paired sample t-test revealed that both the reading and cloze groups had manifested significant enhancement in their knowledge of collocation after the treatments.
\end{abstract}

Index Terms - collocation, collocate, node, receptive task, productive task

\section{INTRODUCTION}

Recently, there has been a widespread consensus among L2 teachers and researchers over the idea of including collocation teaching in the second and foreign language teaching curriculums (Bahns \& Eldaw, 1993; Howarth, 1998; McCarthy \& O'Dell, 2005; Nesselhauf, 2003). Vocabulary of each language consists of single words such as nouns and adjectives and word combinations such as idioms and collocations. Collocations comprise a significant part of native speaker competence, and they need to be given a much attention as given to other areas of the English language when developing materials and designing academic curriculums (Hill, 2000). Due to constant contact with the language, native speakers of English manage to acquire collocations subconsciously, but L2 learners specially English as a foreign language (EFL) learners are deprived of this privilege (Webb \& Kagimoto, 2009). This problem seems to be more noticeable when it comes to the university students majoring in the English language and advanced (EFL) learners (Bahns \& Eldaw, 1993; Biskup, 1992; Nesselhauf, 2003), because they are expected to be as fluent and accurate as possible. Collocations have traditionally been seen as effective tools through learning which the L2 learners can achieve higher levels of fluency and accuracy (Wray, 2000). Given the significance of collocations in L2 learning and how problematic this area of the language could be for EFL/ESL learners, there may be no wonder that the language teachers and researchers have been taking such a great interest in the role of collocations in the English language classes and trying to examine a variety of methods that may best serve in explicitly and effectively teaching English collocations. Despite the widely recognized importance of collocations, not many studies have empirically turned to investigating the best means of teaching collocations in the English classrooms (Webb \& kagimoto, 2009). This study is an attempt to examine the effectiveness of commonly used methods of teaching single words, reading and cloze tasks in explicitly teaching verb-noun collocations in an Iranian English as foreign language learning.

\section{BACKGROUND}

Studies conducted on the collocations can be put under three categories; studies on exploring the nature and classification of collocations of different types, studies aiming at investigate the EFL/ESL learners' knowledge of collocations and the problems they deal with when using collocations and studies addressing the issue of teaching and learning collocation in the English classroom.

As for the first group of the studies, linguists have put forward a variety of definitions for collocations (Firth, 1957, Sinclair, 1991, Baker, 1992, Lewis, 1994, Hill, 2000, Woolard 2000, Nation, 2001). Almost all proposed definitions for collocation have one point in common: they define collocation as the tendency of some words to co-occur on a regular basis and that these words do not co-occur at random and there are restrictions on how words may combine to make collocations (Baker, 1992). Linguists classify collocations in similar ways. Collocations have generally been classified 
either as open and restricted collocations Mahmoud (2005) or lexical and grammatical collocations (Benson \& ILson , 1986, Baker, 1992, Bahns, 1993). Open collocations refer to nodes that can cluster with a wide range of other words e.g. a red car, a small car, an expensive car, etc. Restricted collocations refer to clusters that are fixed or like idioms e.g. kick the bucket, rain cats and dogs, etc. Grammatical collocations consist of content words: a noun, an adjective or a verb plus a preposition or infinitive. Meanwhile, lexical collocations consist of neither prepositions nor infinitives. They comprise only content words. The second group of studies mainly focuses on the L2 learners, knowledge of English collocations and their problems with collocations:

The comprehension of collocations, due to being transparent, doesn't seem to be problematic for the L2 learners, therefore examining the learners' knowledge of collocations and analyzing their problems with collocations we must investigate their production of collocations (Nesselhauf, 2003). Studies conducted on L2 collocations can be divided into two categories. One group tried to examine learners' collocational knowledge using elicitation techniques such as translation tests (Biskup, 1990, 1992; Bahns and Eldaw, 1993) cloze tests (Shei, 1999; Al-Zahrani, 1998), multiple choice tests (Fayez-Hussein, 1990; Arnaud and Savignon, 1997), blank-filling tasks (Aghbar, 1990; Aghbar and Tang, 1991). These studies have been widely criticized for not being able to show the learners' actual knowledge of collocations, because they just require the learners to produce single collocates. To cope with this limitation the other category of studies tried to analyze the learners' collocational knowledge through comparing their writing tasks with those of native speakers of English, thereby giving the learners the opportunity to produce multi-word collocations of different kinds (Fan, 1991; Granger, 1998b; Lorenz, 1999; Howarth, 1998; Kaszubski, 2000; Zhang, 1993). In general, the results of these studies indicated that the learners were suffering from lack of proper knowledge of collocations and collocation is certainly an area of difficulty for most of L2 learners. The findings of these studies all point to the fact collocation is a problematic area of language for L2 learners, hence it has to be attended to in the English classrooms thoroughly.

Recognizing the importance of collocations for L2 learners, researchers in language teaching field started to examine methods of collocation teaching in the English classrooms in different countries. Of the limited number of the studies which have specifically addresses the issue of teaching collocations, most are concerned with investigating the use of computer aided language teaching facilities in collocation teaching. Sun and Wang (2003) used a concordancer program to examine the relative effectiveness of inductive and deductive approaches to learning grammatical collocations at two levels of difficulty in the classroom. The results showed that the inductive group improved significantly more than the deductive group in learning collocation as demonstrated by an error correction test. The level of difficulty of collocation was also found to influence the learning outcome with easy collocations being more suitable for an inductive approach. In a follow-up study, Chan and Liou (2005) also investigated the effects of Web-based concordancing on collocation learning in a CALL classroom. The study used five Web- based practice units, three of which included the use of a bilingual Chinese-English concordancer to teach verb-noun collocations to EFL students. In line with Sun and Wang's (2003) results, they also found that explicit online instruction was effective in promoting EFL learner knowledge of collocation, with results significantly higher for units in which the concordance had been used. Results also showed significant differences in learning between four verb-noun collocation types with concordancers deemed most suitable for use in the instruction of delexicalised verbs and L1-L2 noncongruent verb collocations. Koosha and Jafarpour (2006) investigated the influence of concordancing materials presented through data-driven learning (DDL) on teaching/learning collocation of prepositions; and, to find out if knowledge of collocation of prepositions was different among the different levels of EFL learners' proficiency. Finally, to determine the extent to which Iranian EFL learners' knowledge of collocation of prepositions is affected by their L1. the results of the study indicated that first, the DDL approach proved to be highly effective in the teaching and learning of collocation of prepositions. Second, learners' performance on collocation of prepositions was shown to be positively related to their level of proficiency. Third, the analysis of errors of collocations indicated that Iranian EFL learners tended to carry over their L1 collocational patterns to their L2 production. Some studies have tried to examine the effects of the methods which are commonly used in teaching single-words in traditional classroom contexts. Lin (2002) examined the effects of employing receptive and productive tasks on verb-noun collocation teaching. Participants in this study were divided into two groups of lowerachiever and higher-achiever students. The results of this study indicated that both groups did better on the receptive tests than the productive ones, but lower-achiever student had a slightly better performance on the productive tests that the higher-achiever students after being exposed to the treatments. Tseng (2002) divided about 100 students into two experimental and control groups. The experimental group was exposed to a twelve-week instruction, but the control group didn't receptive any treatment. The participants in this study were required to take pre-test on collocation, write a composition and fill out a questionnaire on collocation learning behaviors. The results this study showed that the students had little awareness towards the concept of collocation. Besides, after the instruction, the experimental group had considerably much better performance on the posttests of collocation than the control group. Webb and Kagimoto (2009) investigated the effects of receptive and productive vocabulary tasks on learning verb-noun collocation. In this study, 145 Japanese participants were assigned into two experimental and one control groups. One experimental group was exposed to receptive treatment and the other one was given productive treatment, but the control group didn't receive any training. When comparing the participants' scores on pre-tests with their scores on post-tests, the results indicated that the tasks proved to be highly effective in teaching English verb-noun collocations to the Japanese EFL 
learners. The current study is an attempt to examine the effects of the modified version of the receptive and productive tasks used in (Webb \& Kagimoto, 2009) on collocation learning in an Iranian EFL learning context.

Research Question:

To what extent are reading and cloze tasks effective as tools for explicitly teaching collocations in the language classroom?

\section{Methodology}

\section{Participants}

About 94 senior and sophomore BA students, majoring in English Translation, participated in this study, Participants were both male and female with the age rages from 19-28, of these 94 students, 64 were assigned to two experimental groups (Reading $=36$, Cloze task $=28$ ) and 30 to one control group. Each experimental group was divided into two sub groups of higher level and lower level based on their scores on the Oxford Placement test.

TABLE 1:

PARTICIPANTS

\begin{tabular}{|l|l|l|}
\hline \multicolumn{2}{|c|}{} & $\mathbf{N}$ \\
\hline Control & 30 \\
\hline \multirow{2}{*}{ Experimental } & Reading & 36 \\
\cline { 2 - 3 } & Cloze task & 28 \\
\hline Total & 94 \\
\hline
\end{tabular}

\section{Design}

To find answer to the research question, an experimental design was arranged. Two weeks before the experiment, all of the participants were administered a pretest testing their receptive knowledge of collocation and based on this pretest target collocations which students were unlikely to know were selected. In the second week, the participants were given a pretest measuring productive knowledge of collocations selected based on the receptive pretest conducted a week before, and then participants were randomly assigned to two receptive and productive experimental groups ( about 64 participants) and one control group( about 30 participants). Next week, in the receptive treatment, the receptive experimental group was given the receptive treatment and the productive group was given the productive treatment collocations in blanks in the same three sentences that the first experimental group had. The participants were closely monitored by the researcher to ensure that the treatments had been completed. Having completed the treatments, the participants were immediately given the receptive and productive posttests. The control group simply completed the posttests measuring receptive and productive knowledge of collocation without being exposed to the treatments.

\section{Materials}

\section{1) Receptive Treatment}

The receptive and productive treatments used in this study were taken from Webb \& Kagimoto, 2009. In the receptive treatment, the students were given collocations alongside their Farsi meaning, each collocation was followed with three glossed sentences with the related collocation in them. The participants were simply asked to try to understand the collocation, which was written in bold, in each of the three glossed sentences. In Example 1 the glossed sentences for the target collocations Pull Strings are shown.

Example 1

pull strings = بارنى بازى كردن

Tony is sure he can pull a few strings and get you in.

Do you want me to pull a few strings for you?

\section{2) Productive Teatment}

In the productive treatment, the students were given the collocations used in the same glossed sentences used in the receptive treatment, though collocations used in each sentence, which was written in bold, were replaced. To complete this treatment, the participants were required to fill in the blanks with the appropriate collocations listed above. The participants' task was to write the two collocations in the correct set of three sentences. Ten sets of two collocations and their sentences were presented in the test Having competed the cloze task, the participants were given an answer sheet which showed the correct collocation beside the appropriate number so that they make sure about whether or not their answers were correct. In Example 2, the cloze tasks for the collocations lose touch and meet demand are shown.

Example 2

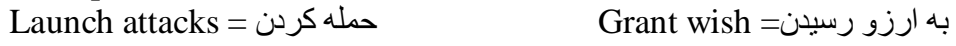

It may be too late to .......... Larry's ....... in time.

I'd happily ........ him his ..........

I'm looking for someone who'll ........ my ........

Turkey might be used as a base from which to ........... on Iraq.

We must make sure we win the ball and then.......... our own .........

From the islands, we will..........the land

3) Receptive Pretest of Collocation 
A pretest measuring receptive knowledge of collocation was used to measure learners' receptive knowledge of collocations and to select collocations that participants were unlikely to know so that they can be used in the study.

Example3
lose
a) touch
b) surprise
c) trouble
d) peace
e) I don't know

4) Productive Pretest of Collocation

In order to measure the participants' productive knowledge of verb-noun collocations, they were given a cloze test in which they were required to complete sentences through providing appropriate verbs for each sentence. A unique feature in his cloze test was, instead of deleting the verb entirely, the first letter/phoneme of the verbs was provided to prevent subjects from making a wild guess, hence assuring better accuracy in the test.

Example 4

Tony is sure he can p.......... a few strings and get you in

5) Immediate Posttest of Productive Knowledge of Collocation

Immediate posttest of productive knowledge of collocation used in this study was taken from Webb \& Kagimoto, 2009. In this test, the participants were given the node words from the target collocations and had to write the collocates, which they had learned in the treatment.

Example 5

Touch ........

6) Immediate posttest of receptive knowledge of collocation

Immediate posttest of receptive knowledge of collocation used in this study was taken from Webb \& Kagimoto, 2009. The test was identical to the pretest designed to select the target collocations. it should be mentioned that both of these immediate receptive and productive posttests were given to the students immediately after completing the treatments.

Example 5
lose
a) touch
b) surprise
c) trouble
d) peace
e) I don't know

\section{RESULTS}

In order to answer the research question, the difference between the participants' scores on pretests and posttests, a paired-sample t-test was conducted to evaluate the impact of the treatments (reading comprehension and cloze tests) on the participants' collocation learning.

The descriptive statistics (means, standard deviation, and number of participants) of the scores for the tests measuring receptive and productive knowledge of collocation are reported in Table 2.

TABLE 2

\begin{tabular}{|c|c|c|c|c|c|c|c|c|c|}
\hline & \multicolumn{9}{|c|}{ Learning Condition } \\
\hline & \multicolumn{3}{|l|}{ Control } & \multicolumn{3}{|l|}{ Reading } & \multicolumn{3}{|l|}{ Cloze } \\
\hline & Total N & Mean & $\begin{array}{l}\text { Standard } \\
\text { Deviation }\end{array}$ & Total N & Mean & $\begin{array}{l}\text { Standard } \\
\text { Deviation }\end{array}$ & Total N & Mean & $\begin{array}{l}\text { Standard } \\
\text { Deviation }\end{array}$ \\
\hline Receptive collocation pretest & 30 & 8.30 & 1.78 & 36 & 7.89 & 2.31 & 28 & 8.07 & 2.76 \\
\hline Receptive collocation posttest & 30 & 8.47 & 1.91 & 36 & 16.83 & 1.83 & 28 & 15.43 & 2.33 \\
\hline Productive collocation pretest & 30 & 8.03 & 2.22 & 36 & 7.50 & 2.37 & 28 & 8.43 & 1.79 \\
\hline Productive collocation posttest & 30 & 8.33 & 2.04 & 36 & 13.54 & 3.45 & 28 & 16.64 & 1.47 \\
\hline
\end{tabular}

Figure 1 shows that the reading groups' mean score increased from 7.89 to 16.83 on the receptive tests after the treatment and the cloze groups' mean score increased from 8.07 to 15.43 on the receptive tests after being exposed to the treatment.
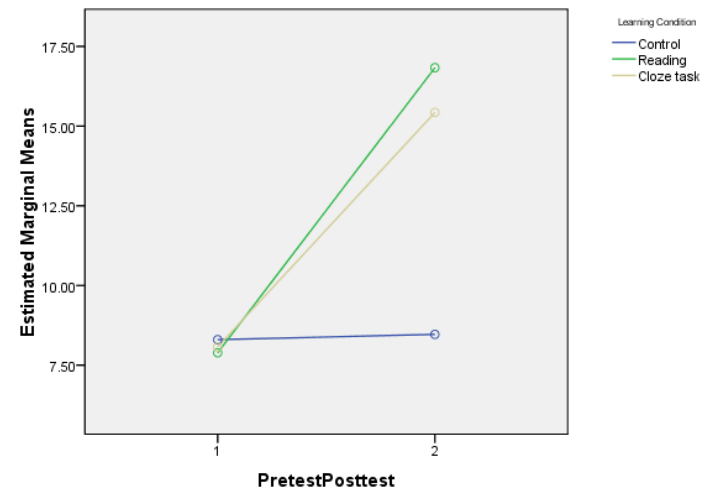

Figure 1. Pretest And Posttest Scores On The Receptive Knowledge Of Collocation Test 
Figure 2 shows that the reading groups' mean score increased from 7.5 to 13.54 on the productive tests after the treatment and the cloze groups' mean score increased from 8.43 to 16.64 on the productive tests after the treatment. In order to determine the effects of the learning conditions.

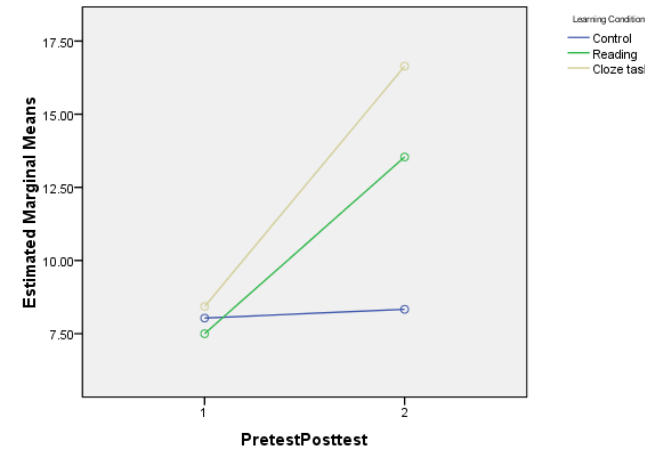

Figure 2. Pretest And Posttest Scores On The Productive Knowledge Of Collocation Test

In order to determine the effects of the learning conditions (completing a cloze task and reading three glossed sentences) on all three groups a paired-samples t-test was conducted, the results of the paired-sample tests revealed that the reading group and the cloze group improved their scores considerably more than the control group.

There was a statistically significant difference between the participants' performance on the pretests and posttests in both reading and cloze groups $(\mathrm{p}<0.05)$. But the difference between the control groups' performance on the pretests and posttests wasn't significant ( $\mathrm{p}>0.05)$.

\section{DISCUSSION}

The findings of this study show that both treatments (completing a cloze task and reading three glossed sentences) proved to be considerably effective methods of learning verb-noun collocations. Mean scores of the reading group on the test measuring productive knowledge of collocation increased from 7.50 to 13.54 and increased from 7.89 to 16.83 on the test measuring productive knowledge of collocation. The students who had been exposed to the cloze treatment had similar performances, scoring 8.43 on the productive pretest and 16.640 n the productive posttest, and their mean score on the test measuring receptive knowledge of collocation increased from 8.07 to 15.43. But the control group did not demonstrate any remarkable improvement on learning collocations, their mean score on the receptive tests increased from 8.30 to 8.47 and from 8.03 to 8.33 on the productive tests. Although earlier research has repeatedly shown that that receptive knowledge is easier to gain than productive knowledge (Waning, 1997a, 1997; Webb, 2005), the findings of this study indicated that the students who did the productive treatment had better performance on productive posttest than receptive posttest, but the converse situation was attested with those participants who did the receptive treatment. Thus it may be mentioned that it is the kind of instruction received by students which has determining roles in gaining receptive or productive knowledge and we cannot simply claim that, as a general rule of thumb, receptive knowledge is easier to gain than productive knowledge.

Dramatic changes in the participants' scores on the posttests in comparison with pretests point to the fact that reading glossed sentences and completing cloze tasks can be used as effective explicit methods of teaching collocations in English classrooms. The results of the pretest study revealed that Iranian English language learners are in lack of necessary knowledge of collocations, and this is in line with the results of previous studies conducted on the EFL learners' knowledge of collocations in different countries (e.g., Channel, 1981; Alkhatib, 1984; Aghbar, 1990; Biscup, 1992; Bahns \& Eldaw, 1993; Farghal \& Obiedat, 1995; Alzahrani's, 1998; Abedi, 1998; Huang, 2001 ). The results of this study, also provide support for previous studies which have investigated the effects of explicit teaching methods of teaching collocations in English classrooms (e.g., Renouf \& sinclair, 1988; Richards \& Rogers, 2001; Sun \& Wang, 2003; Chan \& Liou, 2005).

Previous studies conducted on vocabulary acquisition indicated that productive tasks such as completing a cloze task tend to be more contributing than receptive tasks such as reading three glossed sentences at increasing productive lexical knowledge, and receptive tasks are more effective than productive tasks at increasing receptive lexical knowledge (Stoddard, 1929; Griffin \& Harley, 1997; Waring, 1997b). The findings of this study, on the other hand, revealed no significant difference between the effects of the tasks on learning collocations. This lack of difference between the effects of the tasks may be attributed to following reason. The amount of time spent on receptive and productive tasks seems to be a determining factor in whether a receptive task is more effective or a productive task Webb (2005). In this study, however, there was no time limit for the participants to do the tasks and they were given as much time as they needed to take the tests and therefore they had a chance to spend more time on doing the productive tests and increasing their scores. 


\section{CONCLUSION}

The present study was an attempt to investigate the effects receptive and productive treatments on learning verb-noun collocations. Participants in this study were randomly assigned to productive and receptive groups. The students in the receptive group were given the receptive task, and participants in the productive group were given the productive task. The findings indicated that participants in both groups were able to gain much receptive and productive knowledge of the collocations under study. The participants managed to gain the receptive knowledge of collocations for approximately 17 of the 20 target collocations, and they were able to gain the productive knowledge of collocations for approximately 15 of the 20 collocations. Generally, no significant difference between the two tasks was found.

\section{TEACHING IMPLICATIONS}

The current study has proved that collocations can be taught explicitly in EFL contexts, through using the methods which are usually used to teach single words. Given the role of collocations in improving language learners' fluency and accuracy, teachers need to take explicitly teaching collocations into account. In ESL contexts, just making students aware of the importance of the knowledge of collocations may suffice and teachers can simply instruct students to notice and learn the words that regularly co-occur, because they are likely to have enough exposure to the English language. In an EFL context, however, students are mostly deprived of this chance and teachers should not only make their students aware of the importance of the knowledge of collocations in language learning but they should also try to explicitly teach them in their classrooms

Verb-noun collocations selected for this study were all made up of simple words that all participants were likely to know. The purpose of choosing unknown collocations that are made up of known words was two-facet. First, to teach these collocations to the participants, and to make them aware that vocabulary learning is not just the matter of learning meaning of single words, and they need to pay attention to other aspects of the knowledge of vocabulary which go beyond learning single words. Teachers can use this technique to make their learners aware of the importance of collocations, and thereby encourage them to learn the patterns in which words regularly co-occur.

\section{LIMITATIONS}

The first limitation is related the number of collocations employed in this study. Due to the time constraints, only 20 verb-noun collocations were used in this study to run the treatments. Given that all the students who participated in this study were university students, using more collocations could have made better treatments and more reliable tests measuring the participants' receptive and productive gained knowledge.

The second limitation concerns with the type of collocations used in the present study. The reason why verb-noun collocations were used in this study was that they have proved to be highly problematic for EFL learners (Chan \& Liou, 2005; Nesselhauf, 2003), But other types of collocations such as collocations of prepositions can equally cause difficulty for EFL learners (Koosha \& Jafarpoor, 2006). Thus, the treatments might have been more beneficial to the learners if both kinds of collocations had been used in the design of the study.

The third limitation of the current study pertains to the unlimited amount of the time the participants were given to take the tests. Webb (2005) showed that when there was no time limit for students and they were granted as much time as they wanted to do receptive and peoductive tasks, productive tasks were more effective, however, when there was a time limit the converse situation held true and receptive tasks came to be more effective. Hence, the results of this study might have been different if the participants had faced time limits.

The final limitation of this study is related to the pretest and posttest measuring productive knowledge of the collocations. In order to prevent the participants from having wild guesses, the initial letter of each collocate was provided for the participants, and might have affected the performance on the receptive tests.

\section{SUGGeSTIONS FOR FURTHER RESEARCH}

The following recommendations for further research are based upon the results in this study:

First, the focus of this was investigating the effects of receptive and productive tasks on learning of verb-noun collocations. It is recommended to examine the effects of these tasks on other kinds of collocations such as adjectivenoun collocations or prepositional collocations in further studied to see whether or not the task are effective in learning the other kinds of collocations.

Second, time is an important factor for language learners to function in real life contexts, and they are not likely to have as much time as they want to produce or understand the target language. Thus, it is recommended that for further studies, which attempt to investigate the effects of receptive and productive tasks on language learning, consider controlling the amount of the time learners are allowed to spend on completing the tasks.

Finally, when scoring the participants' responses the translation exam in this study, it was found that $37 \%$ of the participants had resorted to word by word translation instead of writing target collocations they had already learned. This problem may be due to their lack of understanding of the notion of collocations. Therefore, it is recommended that further studies which aim at investigating the methods of collocation teaching should make students aware of what 
collocations are before embarking on teaching collocations to them so that they know what exactly they are required to do when completing the tasks or taking the tests.

\section{ACKNOWLEDGMENT}

The authors are grateful to the Office of Graduate Studies at the University of Isfahan for their support.

\section{REFERENCES}

[1] Aghbar, A.A., (1990). Fixed expressions in written texts: Implications for assessing writing sophistication. In: Paper presented at a Meeting of the English Association of Pennsylvania State System University, October 1990

[2] Aghbar, A.A., Tang, H., (1991). Partial credit scoring of cloze-type items. In: Paper Presented at 1991 Language Testing Research Colloquium, Educational Testing Service, Princeton, NJ, pp. 1-24.

[3] Arnaud, P.J.L., Savignon, S.S. (1997). Rare words, complex lexical units and the advanced learner. In: Coady, J., Huckin, T. (Eds.), Second Language Vocabulary Acquisition: A Rationale for Pedagogy. CUP, Cambridge, pp. 157-173.

[4] Al-Zahrani, M. S. (1998). Knowledge of English lexical collocations among male Saudi college students majoring in English at a Saudi university. Unpublished doctoral dissertation, Indiana University of Pennsylvania, Pennsylvania.

[5] Elkhatib, A. S. A. (1984). A classification of the lexical problems of EFL/ESL students. New York, Report-Research/ Technical. (Eric Document Reproduction Service No. 246 691).

[6] Benson, M., Benson, E., \& Ilson, R. (1986b). The BBI combinatory dictionary of English: A guide to word combination. Amsterdam: John Benjamin.

[7] Baker, M. (1992). In other words. London: Routledge.

[8] Biskup, D. (1992). L1 influence on learners' renderings of English collocations: A Polish/German empirical study. In P. J. L. Amaud \& H. Bejoint (Eds.), Vocabulary and applied linguistics (pp. 85-93). Houndmills: Macmillian.

[9] Bahns, J. \& Eldaw, M. (1993). Should we teach EFL students collocations? System,1(1) 101-114.

[10] Chan, T. P., \& Liou, H. C. (2005). Effects of Web-based concordancing instruction on EFL students' learning of verb-noun collocations. Computer Assisted Language Learning, 18, 231-251.

[11] Channell, L. (1981). Applying semantic theory to vocabulary teaching. English Language Teaching, 35, 115-122.

[12] Farghal, M. \& Obiedat, H. (1995). Collocations: A neglected variable in EFL. 1BAL, 33 (4), 315-333.

[13] Fan, M.Y., 1991. A Study of the Company Kept by a Selection of English Delexical Verbs and the Implications for Teaching of English in Hong Kong. Ph.D. University of Durham, UK.

[14] Firth, J. (1957). Modes of meaning. In J. Firth (Ed.), Papers in linguistics. Oxford: Oxford University Press.

[15] Granger, S. (1998). Prefabricated patterns in advanced EFL writing: Collocations and formulae. In A. P. Cowie. (Ed.), Phraseology: Theory, analysis, and applications (pp. 145-160). Oxford: Oxford University Press.

[16] Hassan Abadi, S. (1998). A lexio-grammatical study of collocations by Iranian EFL learners. Unpublished thesis, English Language Department, Shiraz Azad University: Iran.

[17] Hill, J. (2000). Revising priorities: From grammatical failure to collocational success. In M. Lewis (Ed.), Teaching collocation: Further development in the lexical approach (pp.47-69). Oxford: Oxford University Press.

[18] Howarth, P. (1998). Phraseology and second language proficiency. Applied Linguistics. IS (1), 24-44.

[19] Koosha, M., \& Jafarpour, A. (2006). Data-driven learning and teaching collocation of prepositions. The case study of Iranian EFL adult learners. Asian EFL journal, 8(4), 197-209.

[20] Kaszubski, P. (2000). Selected aspects of lexicon, phraseology and style in the writing of Polish advanced learners of English: a contrastive, corpus-based approach. Retrieved from http://main.amu.edu.pl/przemka/research.html. (10/05/2011)

[21] Lin, Y. P. (2002). The effects of collocation instruction on English vocabulary developments of senior high students in Taiwan. Unpublished Master's thesis, National Kaohsiung Normal University, Taiwan.

[22] Lewis, M. (1993). The lexical approach. Hove, England: Language Teaching Publications

[23] Hammer, J. (1991). The practice of English language teaching. Second Edition. London: Longman.

[24] Lorenz, T.R. (1999). Adjective Intensification - Learners Versus Native Speakers. A Corpus Study of Argumentative Writing. Amsterdam and Atlanta, Rodopi.

[25] McCarthy, M.J. (1984). Anew look at vocabulary in EFL. Applied Linguistics, 5(1), 12-22.

[26] Nation, I.S.P (2001). Learning vocabulary in another language. Cambridge: Cambridge University Press.

[27] Nesselhauf, N. (2003). The use of collocations by advanced learners of English and some implications for teaching. Applied Linguistics, 223. Retrieved February 14, 2011 from ProQuest Direct (ISSN No. 1426001).

[28] O'Dell, F. (1997). Incorporating vocabulary into the syllabus. In N, Schmitt, \& M.McCarthy (Eds), Vocabulary: Description, Acquisition and Pedagogy (pp. 258-278). Cambridge, Cambridge University Press.

[29] Shei, C. C., (1999).A brief review of English verb-noun collocation [sic!]. Retrieved from http://www.dai.ed.ac.uk/homes/shei /survey.html. (15/09/2011)

[30] Sinclair, J. (1991). Corpus concordance collocation. Hong Kong: Oxford University Press.

[31] Sun, Y. \& Wang, L. (2003). Concordancers in the EFL classroom: cognitive approaches and collocation difficulty. Computer Assisted Learning, 16, 83-9.

[32] Tseng. F. P (2002). A study of the effects of collocation instruction on the collocational competence of senior high school students in Taiwan. Unpublished master's thesis, National Taiwan Normal University, Taipei.

[33] Webb, S. (2005). Receptive and productive vocabulary learning: The effects of reading and writing on word knowledge. Studies in Second Language Acquisition, 27, 33-52.

[34] Webb, S. \& Kagimoto, E. (2009). The effects of vocabulary learning on collocation and meaning. TESOL Quarterly, 43, $55-77$.

[35] Woolard, G. (2000). Collocation- encourages learner independence. In M. Lewis (Ed.) Teaching collocation: Further development in the lexical approach (pp.28-46). Oxford: Oxford University Press. 
[36] Wray, A. (2000). Formulaic sequences in second language teaching: Principle and practice. Applied Linguistics, 21, $463-489$.

[37] Zhang. X. (1993). English collocations and their effect on the writing of native and non-native college freshmen. Unpublished doctoral dissertation.

Mehdi Falahi is an MA holder of TEFL at university of Isfahan, Isfahan, Iran. His main areas of research are English Teaching, Discourse Analysis, and Sociolinguistics. He has been engaged in teaching English for nearly six years.

Ahmad Moinzadeh is currently an Assistant Professor of Linguistics at Department of English, Faculty of Foreign Languages, University of Isfahan, Isfahan, Iran. He has instructed BA, MA, and PhD courses at this department for many years. His main areas of research are Syntax, Comparative/Contrastive Linguistics, Morphology, and Language Acquisition. He holds a PhD degree in Linguistics, an MA degree in Linguistics, and a BA degree in English Language and Literature. 